\title{
INVESTIGAÇÃO DE PARÂMETROS FÍSICOS, QUÍMICOS E MICROBIOLÓGICOS PARA AVALIAÇÃO DA QUALIDADE DA ÁGUA DE LAGOS URBANOS DA CIDADE DE CATALÃO-GO
}

\section{Research parameters of physical, chemical and microbiology for assessment of water quality of urban lakes city of Catalão-GO}

PAULA, Heber Martins ${ }^{1}$, MESQUITA, Glenda Máris ${ }^{2}$, MENDES, Márcia Felipe ${ }^{3}$

Recebido em 06 de junho de 201; recebido para revisão em 07 de julho de 2013; aceito em 10 de julho de 2013; disponível on-line em 26 de outubro de 2013.

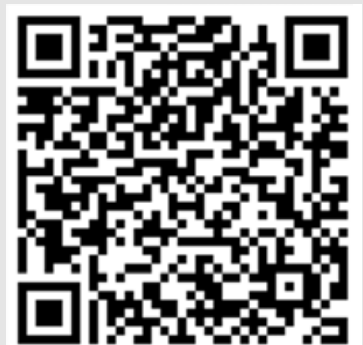

PALAVRAS CHAVES:

Qualidade da água; Lagos urbanos;

Análises físico-químicas da água;

\section{KEYWORDS:}

Water quality; Urban lakes; Physical and chemical water analysis.
RESUMO: A água é de grande importância para a humanidade, assumindo um caráter imprescindível para a sobrevivência dos seres vivos. Entretanto, da mesma forma que a sua presença cria condições para a vida, a qualidade da água pode também representar sérios riscos à saúde. A cidade de Catalão cresceu substancialmente nos últimos trinta anos, causando mudanças profundas no espaço como: desmatamentos, impermeabilização do solo, ocupação de áreas de preservação entre outras. $O$ objetivo do presente trabalho foi investigar a qualidade da água da Represa do Clube do Povo e das Represas do Complexo Ecológico Francisco Cassiano Martins, localizadas na zona urbana da cidade de Catalão-GO. Para tanto foram realizadas análises físicas e químicas $(\mathrm{pH}$, condutividade, turbidez, oxigênio dissolvido, temperatura, salinidade e demanda química de oxigênio) e: microbiológicas (coliformes termotolerantes). Considerando o uso das águas das represas estas se enquadram na classe 2 , segundo Resolução CONAMA 430. Dos parâmetros físicos e químicos analisados apenas o pH apresentou-se fora dos padrões estabelecidos pelos órgãos competentes. A análise de coliformes termotolerantes apresentou resultados que excederam muito o limite máximo estabelecido pela referência, havendo a necessidade de identificação de pontos de contaminação e eliminação dos mesmos. Uma parte a destacar no estudo foi a pesquisa junto à população, observou-se que a mesma não tem preocupação ou conhecimento dos problemas que podem ser causados pelo consumo de peixes provenientes de água contaminada por coliformes. Com os resultados conclui-se que, apesar dos parâmetros físicos e químicos não apresentarem significativas diferenças em relação ao padrão estabelecido, as águas dos lagos em estudo apresentam significativa contaminação microbiológica, sendo necessário o envolvimento do poder público através da implantação de políticas de monitoramento ambiental como forma de controle da qualidade da água.

ABSTRACT: The water is of great importance for humanity, taking on a character essential for the survival of living beings. However, as its presence creates conditions for life, water quality can also pose serious health risks. The Catalan city has grown substantially in the last thirty years, causing profound changes in space as: deforestation, soil sealing, occupancy and other conservation areas. The objective of this study was to investigate the water quality of the dam's Club People and Dams Complex Ecological Cassiano Francisco Martins, located in the urban area of Catalan-GO. Analyzes were performed for both physical and chemical ( $\mathrm{pH}$, conductivity, turbidity, dissolved oxygen, temperature, salinity and chemical oxygen demand) and microbiological (fecal coliform). Considering the use of the waters of these dams fall into class 2 , according to CONAMA Resolution 430. Of physical and chemiical parameters analyzed only $\mathrm{pH}$ showed up outside the standards established by the competent bodies. The analysis of fecal coliform results showed that far exceeded the ceiling set by reference, there is a need to identify points of contamination and disposal. A part of the study was to highlight research on the population, it was observed that it has no concern or knowledge of the problems that can be caused by the consumption of fish from water contaminated by coliforms. With the results it is concluded that despite the physical and chemical parameters do not show significant differences compared to the established standard, the waters of the lakes under study have significant microbiological contamination, requiring public involvement through the implementation of policies of environmental monitoring in order to control water quality. 


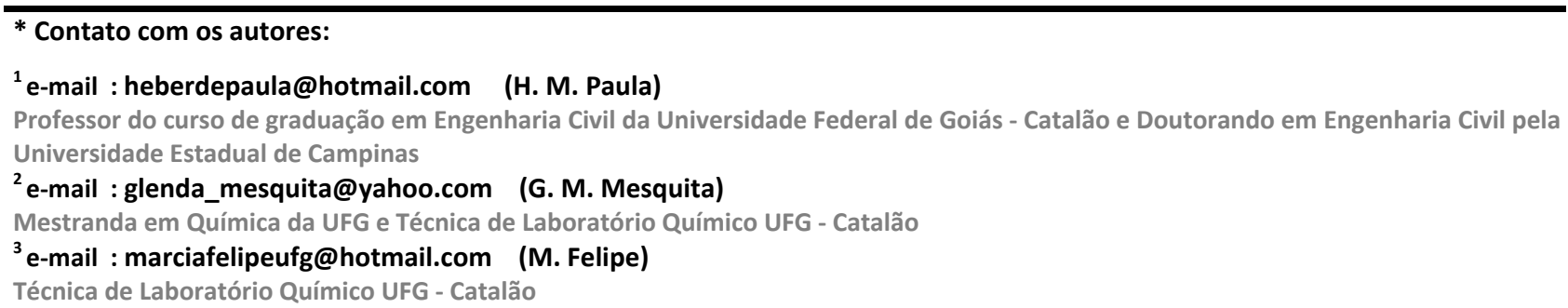

(C) 2013 REEC - Todos os direitos reservados.

\section{INTRODUÇÃO}

O tema água vem cada dia mais ocupando espaço, seja nas discussões do meio científico e acadêmico, seja na sociedade como um todo. Essa crescente preocupação se dá, certamente, pela importância dos recursos hídricos para a sociedade contemporânea, uma vez que a água em quantidade e qualidade é de primordial importância, tanto para a sustentação da espécie, quanto para o desenvolvimento das atividades produtivas da sociedade (OLIVEIRA et al., 2005).

A avaliação de impactos ambientais em ecossistemas aquáticos tem sido realizada através da medição de alterações nas concentrações de variáveis físicas, químicas e microbiológicas. Essas análises são ferramentas fundamentais na classificação e enquadramento de rios e córregos em classes de qualidade de água e padrões de potabilidade e balneabilidade humanas, segundo determinações do CONAMA no 430 (GOULART e CALLISTO, 2003).

As atividades antrópicas, realizadas nas últimas décadas, tais como mineração, construção de barragens e represas, desvio do curso natural de rios, lançamento de efluentes domésticos e industriais não tratados, desmatamento e uso inadequado do solo, entre outros, os ecossistemas aquáticos têm sofrido alterações consideráveis. Com isso, vem sendo verificado uma significativa queda da qualidade da água e perda de biodiversidade aquática, o que resulta na desestruturação do ambiente físico, químico e alteração da dinâmica natural das comunidades biológicas (GOULART e CALLISTO, 2003).

A cidade de Catalão cresceu acelerado entre as décadas de 1990 a 2010, causando mudanças profundas no espaço como: desmatamentos, degradação do Cerrado, queimadas, impermeabilização do solo, exploração de minérios, ocupação de áreas de preservação entre outras (OLIVEIRA et al, 2005). Esse crescimento trouxe uma série de consequências para o Ribeirão Pirapitinga que corta a zona urbana da cidade como, por exemplo, a sua canalização inadequada. Além de ser utilizado como principal coletor de águas pluviais, em seu leito é lançado diariamente uma série de compostos orgânicos provenientes de esgoto sanitário, provocando sua contaminação por bactérias patogênicas (coliformes termotolerantes) ou por substâncias orgânicas e químicas.

O sítio físico no qual a cidade de Catalão se instalou é marcado principalmente pelos elementos naturais da bacia hidrográfica do Ribeirão Pirapitinga e seus afluentes Córrego do Almoço, Córrego do Açude da Chácara e Córrego do Caçador (PDDSUA, 2004). O Ribeirão Pirapitinga nasce no limite urbano de Catalão e atravessa a cidade no sentido leste-oeste, sendo a espinha dorsal da configuração do sítio urbano.

A Represa do Clube do Povo faz parte do Complexo Recreativo Clube do Povo criado em 1984. Este complexo possui um espaço para atender às demandas de lazer e esporte da população da cidade. Neste lago a pesca é realizada nas margens, com utilização de varas, não sendo permitida a utilização de redes ou tarrafas. Com o intuito de evitar acidentes, uma vez que a represa apresenta grande profundidade, a utilização da mesma para natação foi proibida. Também são realizados, aos finais de semana, campeonatos de skates, som automotivo, shows, passeatas e diversas outras formas de lazer.

Na porção noroeste da cidade, escoando-se para o Ribeirão Pirapitinga no sentido leste-sudoeste da cidade encontram-se as nascentes do Córrego do Açude da Chácara. À jusante deste foram construídas em 2004 três represas - Represas do Complexo Ecológico Francisco Cassiano Martins. Estas representam pontos de lazer para a sociedade, pois aos seus redores encontram-se pista para caminhada, uma academia ao ar livre e um pequeno parque para crianças, além disso, a pescaria costuma ser praticada por vários frequentadores.

\section{OBJETIVO}

Observando que os lagos urbanos da cidade de Catalão vem sendo utilizados para pesca e outras atividades de contato primário e secundário, o objetivo deste artigo é identificar possíveis contaminações da 
água destes lagos, através da análise de alguns parâmetros físicos, químicos e microbiológicos. Assim classifica-los segundo a resolução CONANA 430.

\section{MATERIAIS E MÉTODOS}

Os objetos de estudo deste trabalho foram quatro represas localizadas na zona urbana da cidade de Catalão-GO, a Represa do Clube do Povo e as Represas do Complexo Ecológico Francisco Cassiano Martins. As análises e as coletas de água foram realizadas semanalmente nos meses de abril e maio do ano de 2012 entre os dias 01/04 e 12/05. Os pontos de amostragem estão listados na Tabela 1 e identificados no Quadro 1 e na Figura 1.
Quadro 1: Pontos de coleta de amostras de água

\begin{tabular}{|c|l|}
\hline Pontos & \multicolumn{1}{|c|}{ Local } \\
\hline 1 o & Represa do Clube do Povo \\
\hline 2 o & $\begin{array}{l}\text { Primeira Represa do Complexo Ecológico } \\
\text { Francisco Cassiano Martins }\end{array}$ \\
\hline 3 o & $\begin{array}{l}\text { Segunda Represa do Complexo Ecológico } \\
\text { Francisco Cassiano Martins }\end{array}$ \\
\hline 4 o & $\begin{array}{l}\text { Terceira Represa do Complexo Ecológico } \\
\text { Francisco Cassiano Martins }\end{array}$ \\
\hline $5^{\circ}$ & $\begin{array}{l}\text { Primeira Represa do Complexo Ecológico } \\
\text { Francisco Cassiano Martins } \\
\text { (local onde havia aparente despejo de } \\
\text { esgoto) }\end{array}$ \\
\hline
\end{tabular}

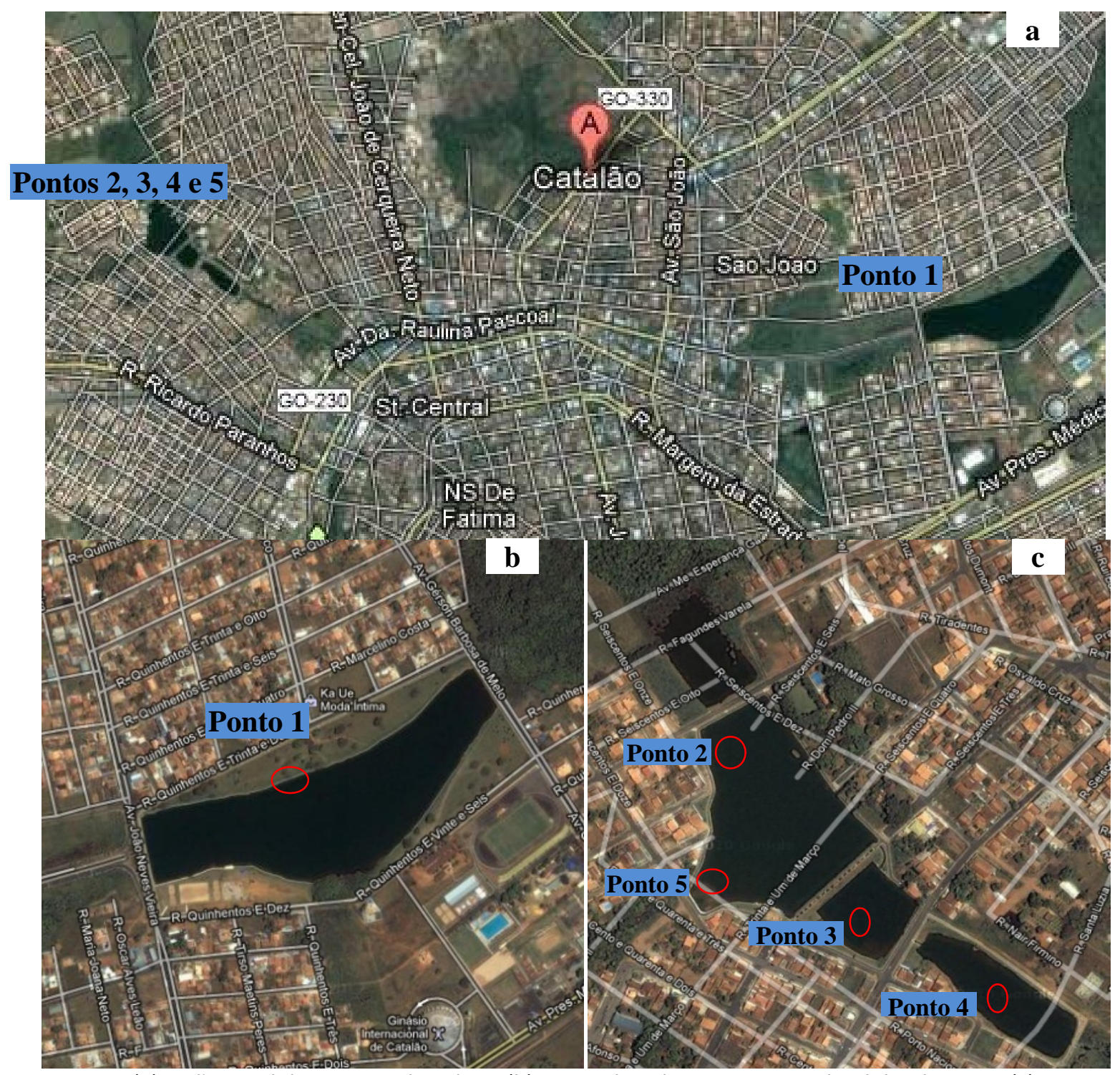

Figura 1: (a) Visão geral dos pontos de coleta. (b) Ponto de coleta 1: Represa do Clube do Povo. (c) Pontos de coleta 2, 3, 4 e 5: Represas do Complexo Ecológico Francisco Cassiano Martins.

Fonte: GOOGLE MAPS (2012). 
Nos pontos de coleta das amostras foram avaliados os seguintes paramentos físicos e químicos: $\mathrm{pH}$, oxigênio dissolvido, temperatura, condutividade elétrica, e salinidade. Esta avaliação foi realizada no local com a utilização de uma sonda multiparâmetros (Water Quality Checker U-10).

Das amostras de água coletadas foi determinada a DQO e realizada análise microbiológica (coliformes termotolerantes). A análise de DQO foi feita com a utilização de frascos de vidro. Nenhum tipo de reagente foi utilizado para a conservação das amostras, pois estas foram levadas diretamente para o laboratório, onde a análise foi imediatamente realizada.

O método de análise utilizado foi o colorimétrico, o qual se baseia na oxidação de redutores pela adição de dicromato, $\mathrm{Cr}_{2} \mathrm{O}_{7}{ }^{2-}$, em excesso. Esta reação ocorre a quente, em meio de ácido sulfúrico, catalisado por íons prata e na presença de mercúrio (este tem função complexante e elimina cloretos). A digestão foi feita a $150{ }^{\circ} \mathrm{C}$ por 120 minutos em bloco digestor (HACH DRB 200). Em seguida, após o resfriamento das amostras, foi realizada a leitura da absorbância com a utilização de um colorímetro (HACH DR/890), concentração de DQO foi determinada através de curva de calibração previamente construída.

As amostras de água para a análise de coliformes termotolerantes foram coletadas em frascos de vidro devidamente esterilizados e levadas, sob resfriamento, diretamente para o laboratório.

A análise realizada foi de caráter qualitativo e quantitativo. As amostras foram homogeneizadas e um mililitro de cada amostra foi transferido para placas de petri esterilizadas. Em seguida, foi adicionado Agar Eosina Azul de Metileno (EMB) previamente fundido, caracterizando o cultivo em profundidade. As placas contendo as amostras foram incubadas invertidas a 37 oC por 48 horas. Posteriormente, foi feita a contagem de colônias, sendo o resultado expresso em Unidades Formadoras de Colônias por 100 mililitros (UFC/100 mL).

Considerando o uso das águas das represas, objetos de estudo deste trabalho, elas deveriam ser enquadradas na classe 2, de acordo com a Resolução CONAMA 430 (BRASIL, 2011). Para águas doces dessa classe são estabelecidos os seguintes limites:

- $\mathrm{pH}$ : entre 6,0 e 9,0;

- Turbidez: até 100 UNT;

- OD: em qualquer amostra, não inferior a $5 \mathrm{mg} \cdot \mathrm{L}^{-1} \mathrm{de}$ $\mathrm{O}_{2}$;

- Salinidade: igual ou inferior a 0,5\%;

- Coliformes termotolerantes: não deverá ser excedido um limite de 1.000 coliformes termotolerantes por $100 \mathrm{~mL}$ em $80 \%$ ou mais de pelo menos 6 (seis) amostras coletadas durante o período de um ano, com frequência bimestral.

Além da qualidade das águas dos lagos urbanos foi realizada uma pesquisa com o intuito de determinar o perfil dos pescadores que utilizam as represas em estudo, bem como avaliar as suas opiniões em relação à qualidade da água. O formulário utilizado está representado pelo Quadro 2.

\begin{tabular}{|c|c|}
\hline \multirow{2}{*}{\multicolumn{2}{|c|}{$\begin{array}{c}\text { UNIVERSIDADE FEDERAL DE GOIÁS - CAMPUS CATALÃO } \\
\text { Questionário - Pesquisa de Campo (foco: pescadores) }\end{array}$}} \\
\hline & \\
\hline \multicolumn{2}{|l|}{ Idade } \\
\hline Sexo & $(\quad) \mathrm{M} \quad(\quad) \mathrm{F}$ \\
\hline \multicolumn{2}{|l|}{ Escolaridade } \\
\hline \multicolumn{2}{|l|}{ Bairro onde mora } \\
\hline \multicolumn{2}{|l|}{ Frequência da pesca } \\
\hline Motivação da pesca & ( ) Lazer ( ) Necessidade \\
\hline Finalidade da pesca & ( ) Esportiva ( ) Alimentação \\
\hline Como avalia a qualidade da água & $\begin{array}{l}\text { ( ) Boa ( ) Regular ( ) Ruim } \\
\text { Obs.: }\end{array}$ \\
\hline Comentários & \\
\hline
\end{tabular}




\section{RESULTADOS E DISCUSSÕES}

Os resultados obtidos nas análises dos parâmetros físicos e químicos, realizadas com a utilização da sonda multiparâmetros, estão listados na
Tabela 1 e os resultados para as análises de DQO e de coliformes termotolerantes nas Tabelas 2 e 3, respectivamente. A concentração de DQO em $\mathrm{mg} \mathrm{L}^{-1}$ foi determinada através da curva de calibração mostrada no gráfico da Figura 2.

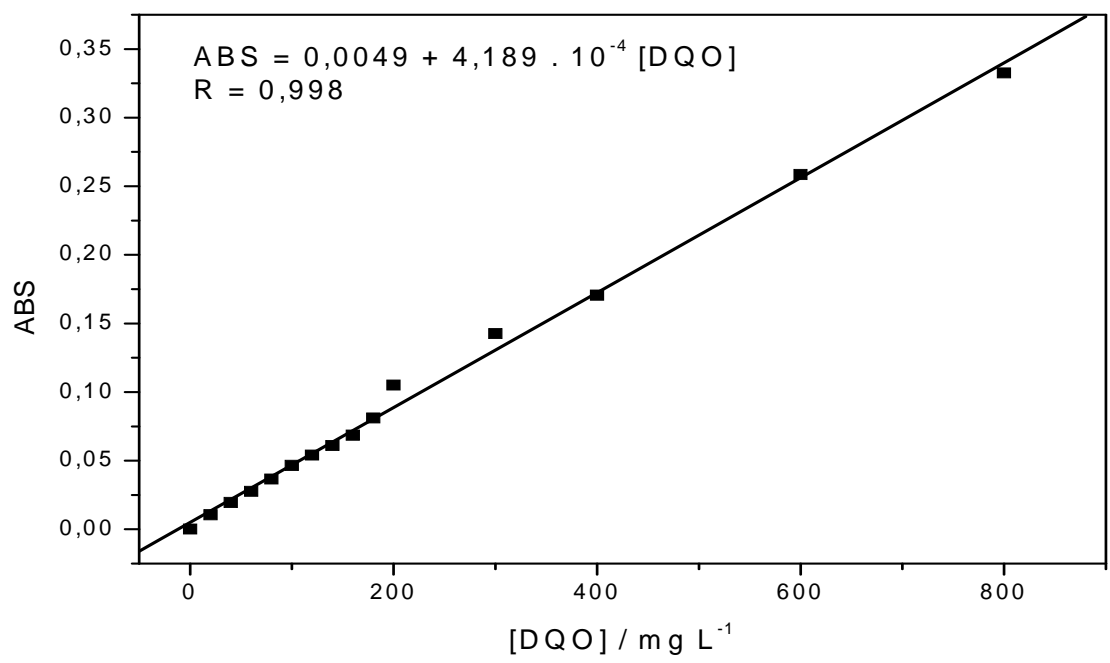

Figura 2: Curva de calibração da DQO.

Tabela 1: Resultados das análises dos parâmetros físicos e químicos.

\begin{tabular}{|c|c|c|c|c|c|c|c|}
\hline Data/Hora & Ponto & $\mathrm{pH}$ & $\begin{array}{l}\text { Condutividade } \\
\left(\mathrm{mS} \mathrm{cm}^{-1}\right)\end{array}$ & $\begin{array}{l}\text { Turbidez } \\
\text { (UNT) }\end{array}$ & $\begin{array}{c}\text { Oxigênio } \\
\text { Dissolvido } \\
\left(\mathrm{mg} \mathrm{L}^{-1}\right)\end{array}$ & $\begin{array}{c}\text { Temperatura } \\
\left({ }^{\circ} \mathrm{C}\right)\end{array}$ & $\begin{array}{c}\text { Salinidade } \\
\text { (\%) }\end{array}$ \\
\hline \multicolumn{2}{|c|}{ Especificações } & $\begin{array}{l}(6,0- \\
9,0) *\end{array}$ & $\begin{array}{c}\left(\leq 0,1 \mathrm{mS} \mathrm{cm}^{-}\right. \\
\left.{ }_{1}\right)^{*}\end{array}$ & $\begin{array}{l}(\leq 100 \\
\text { UNT)* }\end{array}$ & $\begin{array}{c}(\geq 5 \mathrm{mg} \mathrm{L}- \\
\left.{ }_{1}\right) *\end{array}$ & $* * *$ & $(\leq 0,5 \%)^{*}$ \\
\hline \multirow{4}{*}{$\begin{array}{c}01 / 04 / 2012 \\
11: 00\end{array}$} & 1 & 6,80 & 0,025 & 49 & 10,30 & 26,5 & 0,0 \\
\hline & 2 & 6,48 & 0,041 & 61 & 6,45 & 25,6 & 0,0 \\
\hline & 3 & 6,77 & 0,053 & 43 & 7,76 & 27,1 & 0,0 \\
\hline & 4 & 6,84 & 0,054 & 53 & 7,22 & 27,5 & 0,0 \\
\hline \multirow{4}{*}{$\begin{array}{c}08 / 04 / 2012 \\
15: 00\end{array}$} & 1 & 5,47 & 0,043 & 34 & 7,68 & 27,1 & 0,0 \\
\hline & 2 & 5,00 & 0,051 & 21 & 4,74 & 26,1 & 0,0 \\
\hline & 3 & 5,32 & 0,051 & 20 & 5,62 & 26,6 & 0,0 \\
\hline & 4 & 5,50 & 0,053 & 25 & 6,17 & 27,1 & 0,0 \\
\hline \multirow{4}{*}{$\begin{array}{c}15 / 04 / 2012 \\
14: 30\end{array}$} & 1 & 5,62 & 0,030 & 32 & 11,53 & 28,6 & 0,0 \\
\hline & 2 & 4,97 & 0,043 & 16 & 7,45 & 26,9 & 0,0 \\
\hline & 3 & 5,29 & 0,045 & 20 & 7,55 & 27,6 & 0,0 \\
\hline & 4 & 5,33 & 0,053 & 20 & 7,32 & 28,0 & 0,0 \\
\hline \multirow{4}{*}{$\begin{array}{c}22 / 04 / 2012 \\
16: 00\end{array}$} & 1 & 6,10 & 0,027 & 35 & 9,98 & 27,6 & 0,0 \\
\hline & 2 & 5,03 & 0,044 & 21 & 6,03 & 26,6 & 0,0 \\
\hline & 3 & 5,40 & 0,045 & 24 & 7,51 & 27,2 & 0,0 \\
\hline & 4 & 5,96 & 0,027 & 35 & 9,98 & 27,6 & 0,0 \\
\hline \multirow{4}{*}{$29 / 04 / 2012$} & 1 & 5,93 & 0,042 & 29 & 9,89 & 26,3 & 0,0 \\
\hline & 2 & 6,06 & 0,038 & 23 & 6,65 & 27,1 & 0,0 \\
\hline & 3 & 5,65 & 0,045 & 24 & 7,37 & 27,0 & 0,0 \\
\hline & 4 & 5,77 & 0,051 & 24 & 7,81 & 27,2 & 0,0 \\
\hline \multirow{4}{*}{$\begin{array}{c}06 / 05 / 2012 \\
16: 00\end{array}$} & 1 & 5,42 & 0,024 & 38 & 10,43 & 24,1 & 0,0 \\
\hline & 2 & 5,12 & 0,046 & 18 & 7,02 & 24,7 & 0,0 \\
\hline & 3 & 5,29 & 0,049 & 20 & 8,64 & 24,8 & 0,0 \\
\hline & 4 & 5,44 & 0,055 & 26 & 8,63 & 25,0 & 0,0 \\
\hline
\end{tabular}




\begin{tabular}{|c|c|c|c|c|c|}
\hline \multirow{2}{*}{ Data } & \multirow{2}{*}{ Ponto } & DQO & \multirow{2}{*}{ Data } & \multirow{2}{*}{ Ponto } & \multirow{2}{*}{$\frac{\mathrm{DQO}}{\left(\mathrm{mg} \mathrm{L}^{-1}\right)}$} \\
\hline & & $\left(\mathrm{mg} \mathrm{L}^{-1}\right)$ & & & \\
\hline \multicolumn{2}{|c|}{ Especificações } & * & \multicolumn{2}{|c|}{ Especificações } & $*$ \\
\hline \multirow{4}{*}{ 03/04/2012 } & \multirow{4}{*}{\multicolumn{2}{|c|}{$\begin{array}{l}\text { Construção da curva } \\
\text { de calibração }\end{array}$}} & \multirow{5}{*}{ 27/04/2012 } & 1 & 38 \\
\hline & & & & 2 & 21,2 \\
\hline & & & & 3 & 26 \\
\hline & & & & 4 & 18,9 \\
\hline \multirow{4}{*}{$10 / 04 / 2012$} & 1 & 47,5 & & 5 & 26 \\
\hline & 2 & 26 & \multirow{5}{*}{$04 / 05 / 2012$} & 1 & 30,8 \\
\hline & 3 & 23,6 & & 2 & 21,2 \\
\hline & 4 & 28,4 & & 3 & 26 \\
\hline \multirow{5}{*}{$16 / 04 / 2012$} & 1 & 33,2 & & 4 & 16,5 \\
\hline & 2 & 16,5 & & 5 & 30,8 \\
\hline & 3 & 18,9 & \multirow{5}{*}{$12 / 05 / 2012$} & 1 & 28,4 \\
\hline & 4 & 23,6 & & 2 & 21,2 \\
\hline & 5 & 21,2 & & 3 & 26 \\
\hline \multirow{2}{*}{\multicolumn{3}{|c|}{ * Não Regulamentado }} & & 4 & 18,9 \\
\hline & & & & 5 & 33,2 \\
\hline
\end{tabular}

Tabela 3 - Resultados das análises de coliformes termotolerantes.

\begin{tabular}{|c|c|c|c|c|c|}
\hline \multirow{2}{*}{ Data } & \multirow{2}{*}{ Ponto } & Colif. termotolerantes & \multirow{2}{*}{ Data } & \multirow{2}{*}{ Ponto } & \multirow{2}{*}{$\frac{\text { Colif. termotolerantes }}{\text { (UFC/100 mL) }}$} \\
\hline & & (UFC/100 mL) & & & \\
\hline \multicolumn{2}{|c|}{ Especificações } & $(\leq 1000 \text { UFC/100 mL })^{*}$ & \multicolumn{2}{|c|}{ Especificações } & $(\leq 1000 \text { UFC } / 100 \mathrm{~mL})^{*}$ \\
\hline \multirow{4}{*}{ 02/04/2012 } & 1 & 2300 & \multirow{5}{*}{$26 / 04 / 2012$} & 1 & 1800 \\
\hline & 2 & 1900 & & 2 & 1400 \\
\hline & 3 & 1200 & & 3 & 2000 \\
\hline & 4 & 2600 & & 4 & 2100 \\
\hline \multirow{4}{*}{ 09/04/2012 } & 1 & 1400 & & 5 & 6300 \\
\hline & 2 & 2300 & \multirow{5}{*}{ 03/05/2012 } & 1 & 2700 \\
\hline & 3 & 900 & & 2 & 3200 \\
\hline & 4 & 5400 & & 3 & 600 \\
\hline \multirow{5}{*}{$16 / 04 / 2012$} & 1 & 3100 & & 4 & 1400 \\
\hline & 2 & 1000 & & 5 & 1900 \\
\hline & 3 & 1200 & \multirow{5}{*}{$11 / 05 / 2012$} & 1 & 1900 \\
\hline & 4 & 1500 & & 2 & 2500 \\
\hline & 5 & 2400 & & 3 & 1700 \\
\hline \multirow{2}{*}{\multicolumn{3}{|c|}{ * Resolução CONAMA n 430/ 2011}} & & 4 & 1400 \\
\hline & & & & 5 & 3500 \\
\hline
\end{tabular}


A Resolução CONAMA 430 (BRASIL, 2011) não estabelece limites para os parâmetros de condutividade, temperatura e DQO. Segundo CETESB (2009) níveis de condutividade superiores a $0,1 \mathrm{mS} \mathrm{cm}^{-1}$ indicam ambientes impactados e a temperatura dos ambientes aquáticos deve estar entre 0 e $30^{\circ} \mathrm{C}$. A Resolução CONAMA 430 (BRASIL, 2011) estabelece um limite de DBO 5 dias a $20^{\circ} \mathrm{C}$ até $5 \mathrm{mg} \mathrm{L}^{-1}$ de $\mathrm{O}_{2}$.

Fazendo-se uma análise dos resultados obtidos para as análises físicas e químicas realizadas (Tabela 1) pode-se verificar que as variáveis condutividade e salinidade apresentaram resultados dentro do estipulado pelos órgãos competentes. De modo geral, quanto maior a concentração de sais em uma solução, maior sua capacidade de conduzir corrente elétrica. Portanto, conclui-se que os lagos em questão não apresentam quantidades significativas de sais dissolvidos.

Em todos os pontos ocorreram variações da turbidez, porém nenhum valor acima da especificação. Essa variação se deve principalmente pelo vento, pois todos os pontos de análise se localizavam nas margens da represa, apresentando pouca profundidade e permitindo que o movimento da água provocasse o deslocamento do sedimento no fundo do lago. Em todos os dias de análise, principalmente na Represa do Clube do Povo, talvez por ser o ponto mais alto, era perceptível a movimentação das águas, formando pequenas ondas provocadas pelo vento.

O OD apresentou apenas um valor abaixo da especificação, no ponto 2, no dia 08 de abril de 2012. De maneira geral os valores obtidos foram altos, sendo o ponto 1 , em todos os dias, aquele que apresentou maior quantidade. Neste caso a profundidade e o vento contribuíram para esses valores, o movimento da água permite maior contato com o ar e consequentemente maior dissolução de gases. Locais com baixo teor de OD podem indicar alta contaminação por produtos orgânicos e inorgânicos ou alta quantidade de algas.

A temperatura não apresentou grandes variações. Os valores obtidos estavam de acordo com a temperatura ambiente.

O parâmetro $\mathrm{pH}$ apresentou $75 \%$ dos resultados fora da especificação estabelecida pela Resolução CONAMA 430 (BRASIL, 2011). O resultado do ponto 2 no dia 15 de abril de 2012 foi aquele de maior discrepância. O valor encontrado foi de 4,7, o que caracteriza que a água apresenta-se acidificada. Todos os outros pontos também apresentaram valores fora da especificação, sendo que nenhum deles apresentou mais de $30 \%$ das análises dentro dos parâmetros esperados.
Nas águas naturais as variações de $\mathrm{pH}$ podem ser ocasionadas pelo consumo e/ou produção de dióxido de carbono $\left(\mathrm{CO}_{2}\right)$, realizados pelos organismos fotossintetizadores e pelos fenômenos de respiração/fermentação de todos os organismos presentes na massa de água, produzindo ácidos orgânicos fracos. Contudo, os resultados obtidos podem ser devido ao lançamento de matéria orgânica proveniente de esgoto, havendo diminuição do $\mathrm{pH}$ devido à decomposição da mesma (aumento de $\mathrm{CO}_{2}$ liberado durante o metabolismo dos microrganismos). Também a profundidade do lago pode ter influenciado no valor do $\mathrm{pH}$, pois em águas superficiais a dissolução do $\mathrm{CO}_{2}$ é maior do que em águas mais profundas, o que pode conferir certa acidez à água. É importante ressaltar que não choveu nos dias das análises, fato esse que poderia ter contribuído para a variação do $\mathrm{pH}$, pois a água da chuva arrasta contaminantes que alteraram as condições do meio.

Quantos aos resultados de DQO (Tabela 2) o maior valor obtido foi de $47,5 \mathrm{mg} \mathrm{L}^{-1}$ e o menor valor foi $16,5 \mathrm{mg} \mathrm{L}^{-1}$. Porém, não se pode afirmar que os valores estão fora do padrão, pois não há especificações estabelecidas para tal parâmetro. Quando relacionada com a DBO, a DQO pode trazer importantes informações a respeito da carga poluidora presente na água, já que estima o nível total de matéria oxidável. No entanto, a análise de DBO não foi realizada devido à falta de equipamentos necessários e pela dificuldade encontrada na realização de tal análise.

A análise de coliformes termotolerantes (Tabela 3) foi a que apresentou maior número de resultados fora da especificação. Do total de 26 amostras (dos diversos pontos), somente três foram satisfatórios, o que significa dizer que $88,5 \%$ das amostras não estão aptas para o uso ao qual a água se destina. 0 resultado de maior valor (6300 UFC/100 mL), em comparação com a especificação, foi obtido para o ponto 5 no dia $26 / 04 / 2012$. Este ponto se localiza próximo ao despejo aparente de esgoto proveniente de três tubos, podendo ser constatado ainda a presença de contaminantes físicos como sacolas, garrafas PET, óleo. No entanto, alguns pescadores parecem ignorar tais fatos utilizando o local como ponto de pesca.

Os resultados obtidos pelas análises microbiológicas são preocupantes, pois os coliformes termotolerantes indicam suposta presença de dejetos e/ou matéria orgânica, provavelmente, provenientes de esgotos sanitários lançados nas lagoas sem nenhum tipo de tratamento. Os coliformes termotolerantes determinam a origem fecal da contaminação, indicando 
risco da presença de outros microrganismos patogênicos. Microorganismos do grupo coliforme podem apresentar riscos à saúde ocasionando doenças como a febre tifóide, disenterias, cólera, hepatites infecciosas, leptospirose, entre outras e/ou doenças de origem hídrica como a escabiose e outras. É importante ressaltar que não choveu nos dias anteriores das análises, ou seja, não houve alteração das condições do meio em função de produtos carreados pela água da chuva.

A pesquisa de campo revelou informações importantes sobre o perfil dos pescadores. Foram entrevistadas 80 pessoas, os resultados estão listados na Tabela 4.

Apesar da maioria dos pescadores $(85,7 \%)$ apresentarem idade superior a 40 anos, este item varia bastante, sendo comum até mesmo a presença de crianças. Cerca de $42,8 \%$ dos frequentadores possuem até o 1 ㅇ grau completo e $28,6 \%$ possuem o 20 grau. A porcentagem de analfabetos, $14,3 \%$, se igualou à porcentagem de pescadores com curso superior. Quanto à frequência, 80,0 \% afirmam pescar de duas a quatro vezes ao mês, os outros $20 \%$ raramente praticam a atividade no local. A pescaria é praticada por lazer por $81,0 \%$ dos entrevistados, $19,0 \%$ pescam porque gostam e também por necessitarem do peixe para complementação da dieta. A pesca esportiva é praticada por 14,3 \% e $85,7 \%$ consomem o peixe. Em relação à qualidade da água, 47,6 \% acreditam que seja de boa qualidade, $42,8 \%$ a classificam como regular e 9,6\% como ruim. A pesquisa também revelou que $90,0 \%$ dos entrevistados residem em bairros periféricos e são provenientes de classes sociais mais humildes, apenas $10,0 \%$ residem em bairros centrais ou outras cidades. A maioria deles acredita que a água tem boa qualidade e afirmam não há despejo de esgoto nas represas em questão.

Tabela 4: Resultados do questionário de campo.

\begin{tabular}{c|c|c}
\multirow{2}{*}{ Idade } & $>40$ anos & Porcentagem (\%) \\
\cline { 2 - 3 } & $<40$ anos & $85,7 \%$ \\
\hline \multirow{2}{*}{ Escolaridade } & Analfabeto & $14,3 \%$ \\
\cline { 2 - 3 } & Até 1o grau & $14,3 \%$ \\
\cline { 2 - 3 } & 2 2o grau & $42,8 \%$ \\
\hline \multirow{2}{*}{ Frequência da Pesca } & Superior & $28,6 \%$ \\
\cline { 2 - 3 } & De 2 a 4 vezes ao mês & $14,3 \%$ \\
\hline \multirow{2}{*}{ Motivação da Pesca } & Raramente & $80,0 \%$ \\
\cline { 2 - 3 } & Lazer & $20,0 \%$ \\
\hline \multirow{2}{*}{ Finalidade da pesca } & Lazer / Necessidade & $19,0 \%$ \\
\cline { 2 - 3 } & Alimentação & $85,7 \%$ \\
\hline \multirow{2}{*}{ Qualidade da água } & Esportiva & $14,3 \%$ \\
\cline { 2 - 3 } & Boirro onde mora & $47,6 \%$ \\
\cline { 2 - 3 } & Bairros centrais ou outras cidades & $10,0 \%$ \\
\hline
\end{tabular}




\section{CONCLUSÕES}

De acordo com a utilização das águas das represas em estudo estas deveriam se enquadrar na classe 2. No entanto, os resultados das análises microbiológicas apresentaram quantidades de coliformes termotolerantes acima do permitido para esta classe. Diante disso, as águas das represas em questão devem ser classificadas como classe 4, devendo ser destinadas à navegação e à harmonia paisagística (BRASIL, 2005).

A presença de coliformes termotolerantes pode ser devido ao despejo de esgoto sanitário. No caso da Represa do Clube do Povo não foram constatadas tubulações que possam ser responsáveis pelo lançamento, no entanto, a contaminação física é evidente tanto nas margens quanto no interior da mesma. Já nas Represas do Complexo Ecológico Francisco Cassiano Martins verificou-se a presença de tubos que supostamente indicam o despejo (ponto 5), uma vez que o mesmo era visível e não proveniente da água de chuva. Foi constatada contaminação física tanto nas margens quanto nos interiores das represas. Um fato que despertou atenção foram algumas casas construídas na margem da terceira represa, cujos quintais não apresentam muros de fundo, ou seja, tem acesso direto à represa.

Os coliformes termotolerantes são causadores de uma série de doenças, apresentando sérios riscos à saúde. Portanto, as atividades de contato primário, como a pesca, e principalmente o consumo do peixe, devem ser provisoriamente evitadas. A pesquisa junto à população revelou que a mesma não tem preocupação ou conhecimento dos problemas que podem ser causados devido ao consumo de peixes provenientes de água contaminada com coliformes.

A determinação da origem da contaminação é de primordial importância, sendo função do poder público municipal propor as ações mitigadoras. Sugerese que esse projeto seja apresentado às secretarias de meio ambiente e lazer do município para que sejam implantadas políticas de monitoramento ambiental dos lagos. Assim, será possível o controle da qualidade da água e, principalmente, prevenir possíveis epidemias ou contaminação da população devido à alteração da qualidade da água.

\section{REFERÊNCIAS BIBLIOGRÁFICAS}

CONSELHO NACIONAL DE MEIO AMBIENTE. Resolução no 430 de 13 de maio de 2011. Dispõe sobre as condições e padrões de lançamento de efluentes, complementa e altera a Resolução n. 357, de 17 de março de 2005, do CONAMA. D.O.U. Brasília, n.92. p. 89.
CETESB (Companhia de Tecnologia de Saneamento Ambiental). Significado ambiental e sanitário das variáveis de qualidade das águas e dos sedimentos e metodologias analíticas e de amostragem. Companhia Ambiental do Estado de São Paulo, São Paulo, 2009. Disponível em: <http://www.cetesb.sp.gov.br/userfiles/file/agua/aguassuperficiais/variaveis.pdf> Acesso em: 29/06/2012.

GOOGLE MAPS. Catalão - Goiás. 2012. Disponível em: < http://maps.google.com.br/> Acesso em: 04/07/2012.

GOULART, M. e CALLISTO, M. Bioindicadores de qualidade de água como ferramenta em estudos de impacto ambiental. Revista da FAPAM, ano 2, $\mathrm{n}^{\circ} 1,2003$. Disponível em: <http:// www.icb.ufmg.br/big/beds/arquivos/goulartecallisto.pdf> Acesso em: 02/07/2012.

OLIVEIRA, A. L.; VENÂNCIO, M.; MENDONÇA, M. R.; PEDROSA, L. E. A degradação ambiental decorrente da expansão urbana: um estudo de caso - Catalão/GO. $X$ Encontro de Geógrafos da América Latina. Universidade de São Paulo, 2005.

PDDSUA - PLANO DIRETOR DE DESENVOLVIMENTO SUSTENTÁVEL URBANO E AMBIENTAL DE CATALÃO. Prefeitura Municipal de Catalão. Promulgado em 05 de agosto de 2004. 2004.

Crédito de imagens

MESQUITA, G. M.; MENDES, M. F. Figuras do artigo. 2012. 